\title{
TriatoScore: an entomological-risk score for Chagas disease vector control-surveillance
}

\author{
Gilmar Ribeiro- $\mathrm{Jr}^{1 *}{ }^{*}$, Fernando Abad-Franch ${ }^{2 \dagger}$, Orlando M. F. de Sousa ${ }^{3}$, Carlos G. S. dos Santos ${ }^{1}$, \\ Eduardo O. L. Fonseca ${ }^{4}$, Roberto F. dos Santos ${ }^{5}$, Gabriel M. Cunha ${ }^{6}$, Cristiane M. M. de Carvalho ${ }^{6}$, \\ Renato B. Reis ${ }^{7}$, Rodrigo Gurgel-Gonçalves ${ }^{2,8^{*}+}$ and Mitermayer G. Reis ${ }^{1,9,10^{*+}}$
}

\begin{abstract}
Background: Triatomine bugs transmit Chagas disease across Latin America, where vector control-surveillance is increasingly decentralized. Locally run systems often deal with highly diverse native-vector faunas — plus, in some areas, domestic populations of non-native species. Flexible entomological-risk indicators that cover native and nonnative vectors and can support local decision-making are therefore needed.

Methods: We present a local-scale entomological-risk score ("TriatoScore") that leverages and builds upon information on the ecology-behavior and distribution-biogeography of individual triatomine bug species. We illustrate our approach by calculating TriatoScores for the 417 municipalities of Bahia state, Brazil. For this, we (i) listed all triatomine bug species recorded statewide; (ii) derived a "species relevance score" reflecting whether each species is native/ non-native and, if native, whether/how often it invades/colonizes dwellings; (iii) mapped each species' presence by municipality; (iv) for native vectors, weighted presence by the proportion of municipal territory within ecoregions occupied by each species; (v) multiplied "species relevance score" $\times$ "weighted presence" to get species-specific "weighted scores"; and (vi) summed "weighted scores" across species to get municipal TriatoScores. Using standardized TriatoScores, we then grouped municipalities into high/moderate/low entomological-risk strata.

Results: TriatoScores were higher in municipalities dominated by dry-to-semiarid ecoregions than in those dominated by savanna-grassland or, especially, moist-forest ecoregions. Bahia's native triatomines can maintain high to moderate risk of vector-borne Chagas disease in 318 (76.3\%) municipalities. Historical elimination of Triatoma infestans from 125 municipalities reduced TriatoScores by 27\% (range, 20-44\%); eight municipalities reported T. infestans since Bahia was certified free of Trypanosoma cruzi transmission by this non-native species. Entomological-risk strata based on TriatoScores agreed well with Bahia's official disease-risk strata, but TriatoScores suggest that the official classification likely underestimates risk in 42 municipalities. Of 152 municipalities failing to report triatomines in 20062019, two and 71 had TriatoScores corresponding to, respectively, high and moderate entomological risk.
\end{abstract}

\footnotetext{
*Correspondence: gilmarribeirojr@gmail.com; gurgelrg@hotmail.com; mitermayer.reis@fiocruz.br

${ }^{\dagger}$ Gilmar Ribeiro-Jr and Fernando Abad-Franch contributed equally to this work

${ }^{\dagger}$ Mitermayer G. Reis and Rodrigo Gurgel-Gonçalves are joint senior

authors

${ }^{1}$ Instituto Gonçalo Moniz, Fiocruz Bahia, Salvador, Bahia, Brazil

${ }^{2}$ Núcleo de Medicina Tropical, Faculdade de Medicina, Universidade de Brasília, Brasília, Distrito Federal, Brazil

Full list of author information is available at the end of the article
} permits use, sharing, adaptation, distribution and reproduction in any medium or format, as long as you give appropriate credit to the original author(s) and the source, provide a link to the Creative Commons licence, and indicate if changes were made. The images or other third party material in this article are included in the article's Creative Commons licence, unless indicated otherwise in a credit line to the material. If material is not included in the article's Creative Commons licence and your intended use is not permitted by statutory regulation or exceeds the permitted use, you will need to obtain permission directly from the copyright holder. To view a copy of this licence, visit http://creativecommons.org/licenses/by/4.0/. The Creative Commons Public Domain Dedication waiver (http://creativeco mmons.org/publicdomain/zero/1.0/) applies to the data made available in this article, unless otherwise stated in a credit line to the data. 
Conclusions: TriatoScore can help control-surveillance managers to flexibly assess and stratify the entomological risk of Chagas disease at operationally relevant scales. Integrating eco-epidemiological, demographic, socioeconomic, or operational data (on, e.g., local-scale dwelling-infestation or vector-infection frequencies, land-use change and urbanization, housing conditions, poverty, or the functioning of control-surveillance systems) is also straightforward. TriatoScore may thus become a useful addition to the triatomine bug control-surveillance toolbox.

Keywords: Chagas disease, Triatominae, Vector control, Vector surveillance, Risk stratification

\section{Background}

Public health researchers, managers, policy-makers, and international agency officials make regular use of indices or indicators of population health and well-being $[1,2]$. Such indices range from simple counts or rates of disease cases or events to more complex measurements of human development or socioeconomic deprivation [13]. Health-related indices aim primarily at summarizing population-level information on health and disease, on disease risk or exposure, or on the performance of health systems, policies or interventions in a given place (from local to global) and over a given time period (from weeks to centuries) $[1,2]$. In the case of insect-borne diseases, entomological indices are essential to guide control-surveillance efforts [4-8].

Chagas disease is among the most important vectorborne diseases in the Americas; estimates for 2019 suggest that about 6.4 million people (95\% uncertainty interval [UI], 5.5-7.3 million) are infected with its causal agent, Trypanosoma cruzi, in Latin America, leading to annual losses of $\sim 274,000$ disability-adjusted life years (UI, 170,000-490,000) [9-11]. Trypanosoma cruzi is transmitted by $140+$ species of blood-sucking triatomine bugs, and vector control-surveillance is, together with blood- and organ-donor screening, the cornerstone of disease prevention [7, 8, 11, 12]. Entomological indices are critical for the planning, running, and evaluation of Chagas disease vector control-surveillance systems $[7,8]$. In particular, for a given vector species, place, and time period, the World Health Organization advocates the use of indices measuring (i) vector presence, breeding, and abundance inside and/or around houses (indexed by, respectively, infestation, colonization, and density); (ii) vector infection with T. cruzi; and (iii) "dispersion" across localities within a given territory-an index that helps measure progress towards local elimination of non-native species (see definitions in $[7,8]$ ).

Each of these entomological-risk indices, however, has important practical limitations. The most general setback is that, to calculate them, control managers need to regularly organize expensive area-wide, door-to-door surveys that are difficult to maintain in resource-limited settings $[11,12]$. Even in the hands of highly trained staff, moreover, routine vector and parasite detection methods have imperfect sensitivity, and indices that rely on those methods will almost always be biased down $[12,13]$. In particular, there is growing evidence that (i) not all vectors will be detected during routine dwelling inspections, especially after insecticide spraying reduces bug densities [13-15], and (ii) not all T. cruzi infections will be detected during routine vector testing [16]. To further complicate things, local control-surveillance systems frequently deal with a wide variety of native triatomine bug species-plus, at times, introduced populations of non-native species $[11,12,17-20]$. Because different triatomine bug species or populations can play very different roles in disease transmission, control-surveillance tactics must be tailored to the local vector fauna $[11,12$, 19, 20]. Although working classifications of Chagas disease vectors are available for this purpose [7, 19], they often (i) lack the flexibility needed to track key timevarying events (such as, say, the local elimination of non-native species and their replacement by less-known native vectors) and (ii) tend to conflate biological and operational considerations, which makes them confusing and potentially ineffective $[11,12,20,21]$.

In the current context of decentralized health systems across Latin America, Chagas disease vector controlsurveillance decisions are increasingly made at the local level $[22,23]$. Flexible entomological-risk indicators that work well for both native and non-native vector species and that can support local, timely decision-making are therefore needed [20]. Here, we present an entomological-risk score ("TriatoScore") that leverages and builds upon information on the ecology, behavior, distribution, and biogeography of individual triatomine bug species and can help control-surveillance managers to assess, stratify, map, and monitor Chagas disease entomological risk at operationally relevant scales. To illustrate the use of TriatoScore in practice, we applied our approach to the 417 municipalities of Bahia state, Brazil, where native vectors are highly diverse and Chagas disease remains a major public health concern.

\section{Methods}

We aimed at deriving an entomological-risk score based on vector species potentially involved in Chagas disease transmission at the relatively fine scale matching the 
needs of decentralized control-surveillance [23]. This raised two general issues. First, we needed to allow for the sharp differences in epidemiological relevance across vector species $[7,19,24]$. To do this, we combined the hierarchical working classification of triatomine bug species, populations, foci, and individuals proposed by one of us (see [20] and Table 1) with current knowledge about the ecological-behavioral features that drive such interspecies differences [7, 11, 12, 18, 19, 24-26]. Second, we needed to derive a reliable picture of each species' geographic distribution. Because local-scale bug presence data are almost inevitably incomplete, we complemented actual records (see below and [27-33]) with the best available knowledge about the ecoregional biogeography of each species-following $[17,34]$ and hence based on Dinerstein et al's proposal $[35,36]$. We then applied this approach to the $400+$ municipalities of the northeastern Brazilian state of Bahia; below we (i) briefly describe the setting and data used for this illustrative study; (ii) provide a step-by-step guide to calculating municipality-specific entomological-risk scores ("TriatoScores"); and (iii) show how TriatoScores can then be used to flexibly stratify and map Chagas disease entomological risk at the municipality scale.

\section{Study setting and triatomine bug data}

The state of Bahia, Brazil, has 417 municipalities in $\sim 565,000 \mathrm{~km}^{2}$ and nearly 15 million residents, of which $\sim 30 \%$ (or $\sim 4.5$ million people) live in rural areas [37]. By the time the last demographic census was conducted by the Brazilian Instituto Nacional de Geografia e Estatística (IBGE; 2010), about $60 \%$ of houses in the state were considered to be in poor (57\%) or very poor condition (3\%) [37]. Bahia's natural vegetation cover corresponds to nine ecoregions $[35,36]$ that can be grouped into three major habitat classes-drysemiarid (Caatinga and Atlantic dry forest), savannagrassland (Cerrado and Campos Rupestres), and moist forests (Bahia coastal and interior forests, Pernambuco interior forest, and coastal Restingas and

Table 1 Triatomine bug species in Bahia state, Brazil: "species relevance score" based on the approach of Abad-Franch [20]

\begin{tabular}{|c|c|c|c|c|c|}
\hline \multirow[t]{2}{*}{ Species or species pair } & \multicolumn{4}{|c|}{ Hierarchical level } & \multirow{2}{*}{$\begin{array}{l}\text { Species } \\
\text { relevance } \\
\text { score }\end{array}$} \\
\hline & Species & Populations & Foci & Individuals & \\
\hline Triatoma infestans ${ }^{\mathrm{a}}$ & Non-native & Non-wild & Domestic/peridomestic & In foci & 10 \\
\hline Triatoma rubrofasciata & Non-native & Non-wild & Domestic/peridomestic & In foci & 5 \\
\hline Triatoma juazeirensis/brasiliensis ${ }^{\mathrm{b}}$ & Native & Wild/non-wild & Domestic/peridomestic & In foci/invaders & 4 \\
\hline Triatoma sordida & Native & Wild/non-wild & Peridomestic/domestic & In foci/invaders & 4 \\
\hline Triatoma pseudomaculata & Native & Wild/non-wild & Peridomestic/domestic & In foci/invaders & 4 \\
\hline Panstrongylus megistus & Native & Wild/non-wild & Peridomestic/domestic & In foci/invaders & 4 \\
\hline Triatoma lenti/bahiensis ${ }^{b}$ & Native & Wild/non-wild & Peridomestic/domestic & Invaders/in foci & 4 \\
\hline Triatoma vitticeps & Native & Wild/non-wild & Peridomestic/rarely domestic & Invaders/in foci & 3 \\
\hline Triatoma costalimai & Native & Wild/non-wild & Peridomestic/rarely domestic & Invaders/in foci & 3 \\
\hline Panstrongylus lutzi & Native & Wild/non-wild & Peridomestic/rarely domestic & Invaders/in foci & 3 \\
\hline Rhodnius neglectus & Native & Wild/non-wild & Peridomestic/rarely domestic & Invaders/in foci & 3 \\
\hline Rhodnius nasutus & Native & Wild/non-wild & Peridomestic/rarely domestic & Invaders/in foci & 3 \\
\hline Triatoma melanica & Native & Wild/non-wild & Peridomestic/rarely domestic & Invaders/in foci & 3 \\
\hline Triatoma tibiamaculata & Native & Wild & Natural & Frequent invaders & 3 \\
\hline Panstrongylus geniculatus & Native & Wild & Natural & Frequent invaders & 3 \\
\hline Triatoma petrocchiae & Native & Wild & Natural & Invaders & 2 \\
\hline Triatoma sherlocki & Native & Wild & Natural & Invaders & 2 \\
\hline Triatoma melanocephala & Native & Wild & Natural & Invaders & 2 \\
\hline Panstrongylus diasi & Native & Wild & Natural & Invaders & 2 \\
\hline Panstrongylus lenti & Native & Wild & Natural & Invaders & 2 \\
\hline Cavernicola pilosa & Native & Wild & Natural & Rare invaders & 1 \\
\hline Rhodnius domesticus & Native & Wild & Natural & Rare invaders & 1 \\
\hline Psammolestes tertius & Native & Wild & Natural & Rare invaders & 1 \\
\hline Parabelminus yurupucu & Native & Wild & Natural & Rare invaders & 1 \\
\hline
\end{tabular}

${ }^{\text {a }}$ The most dangerous domestic vector of Trypanosoma cruzi

${ }^{b}$ Merged because most records available do not distinguish the species within each pair; we note that (i) most, if not all, "T. brasiliensis" records from Bahia most likely refer to T. juazeirensis, and (ii) genetic similarity between T. lenti and T. bahiensis suggest they might be conspecific [17] 


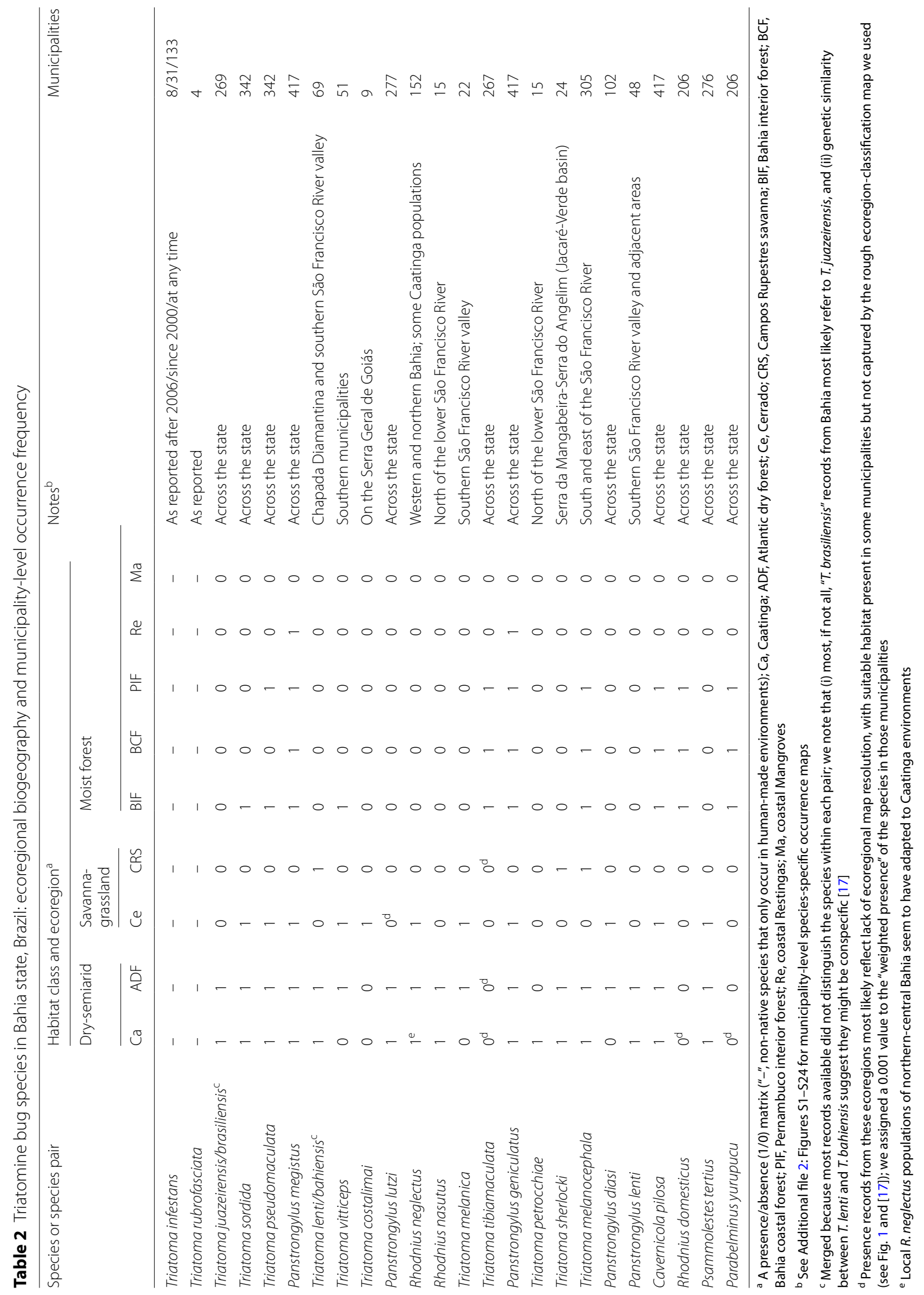




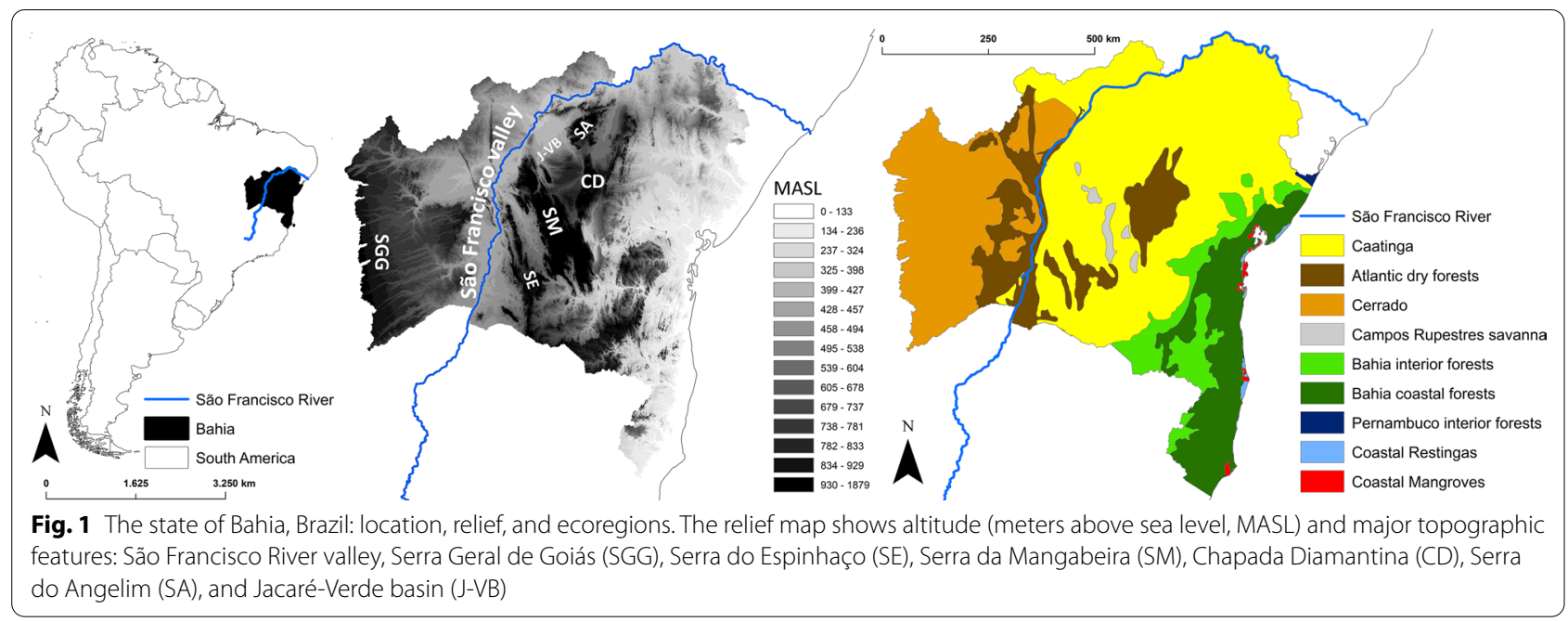

Mangroves) (see Table 2, Fig. 1 and [36]). Twenty-six triatomine bug species, of which 24 are known to be native to the state's territory, have so far been recorded in Bahia [27-33] (Tables 1, 2). Bahia's state health department (SESAB hereafter) uses entomological, epidemiological, demographic, socioeconomic and environmental indicators to group municipalities into three Chagas disease risk strata [32, 38, 39]; currently, 101 municipalities are considered at "low" disease risk, 214 at "moderate" risk, and 102 at "high" disease risk [38]. Recent estimates by the Global Burden of Disease (GBD) study suggest that $\sim 220,000$ people (UI, $\sim$ 190,000-259,000) may carry T. cruzi in Bahia, with $\sim 5.9-7.5$ thousand new infections and $\sim 300-1000$ deaths attributable to Chagas disease occurring annually since 2010 [10].

We used two main sources of information to map triatomine bug species occurrence across Bahia's municipalities: (i) routine control-surveillance records (1999-2019) from SESAB, and (ii) published reports providing either (a) occurrence records at the ecoregion or locality/municipality level $[17,27-34]$ or (b) species distribution maps based on ecological niche models [29, $31,40-45]$. Because many of the records available do not distinguish either Triatoma juazeirensis from T. brasiliensis or T. lenti from T. bahiensis, we treated the former pair as "T. juazeirensis/brasiliensis" and the latter pair as "T. lenti/bahiensis". Thus, our analyses cover 24 taxa-22 individual species and two species-pairs (Tables 1,2). For simplicity, in what follows we will use "species" to refer to these taxa. We note that (i) current knowledge suggests that " $T$. brasiliensis" records from Bahia most likely refer to T. juazeirensis $[17,29,40]$ and (ii) genetic similarity between $T$. lenti and T. bahiensis suggest they might be conspecific [17].
Calculating municipal TriatoScores: step-by-step procedure Calculation of TriatoScores for the 417 municipalities of Bahia state involved the following six steps:

i. List all triatomine bug species recorded statewide (see above and Table 1);

ii. Derive a "species relevance score", based on [20], reflecting whether each species (a) is native or nonnative to the region under consideration (here, the state of Bahia), and, if native, (b) whether and how often it invades or colonizes human habitats. This "species relevance score", hence, roughly measures the known epidemiological relevance of each taxon (see Table 1 and [20]);

iii. Tabulate each species' presence/absence (coded $1 / 0$, respectively) by municipality (see above and Additional file 1: Table S1). Our main analyses were done with the dataset including $T$. infestans records since 2006, which is when Brazil was certified free of T. cruzi transmission by this non-native species [12]; complementary analyses were done (a) with data on native vector species only and (b) with all historical records of $T$. infestans (Additional file 1: Table S1);

iv. For native vectors (Table 1), weight presence/ absence by the extent of municipal territory within ecoregions occupied by each species (see above and Table 2). To compute these "weighted presence" values, we first used municipal [46] and ecoregion shapefiles [36] to calculate, for each municipality, the proportion of territory within each ecoregion (see Table 2 and Additional file 1: Table S2). Then, we multiplied each species' presence (1) or absence (0) by the sum of municipality-specific ecoregion proportions. For each species, therefore, munici- 
pal "weighted presence" values range from 0 to 1 (Additional file 1: Table S3). We used ArcMap ${ }^{\circledR}$ 10.5 [47] both to calculate ecoregion territorial shares and to map "weighted presence" values (see Additional file 2: Figures. S1-S24);

v. For each species and municipality, multiply "species relevance score" by "weighted presence" to get "weighted scores" (Additional file 1: Table S4); and

vi. Sum "weighted scores" across species to get municipal TriatoScores (Additional file 1: Tables S4, S5).

\section{Entomological-risk assessment: stratification, mapping, and spatial analysis}

We standardized TriatoScores (to mean 0 and SD 1) and grouped municipalities into three strata of entomological risk: "high" risk (TriatoScores above 1 SD from the overall mean), "moderate" risk (TriatoScores within \pm 1 SD from the overall mean), and "low" risk (TriatoScores below 1 SD from the overall mean) (Additional file 1: Table S5). Note that, with this standardization-based procedure, entomological risk is evaluated, for each municipality, relative to the overall (average) risk across the state. Thus, if the TriatoScore of any municipality changes over time (because, say, one non-native species is eliminated-or newly recorded), then the statewide TriatoScore mean and SD will change also, potentially leading to some municipalities moving from one entomological-risk stratum to another. In other words, our approach to entomological-risk classification is fundamentally dynamic-it will highlight municipalities that are substantially above, substantially below, or close to the average risk at the time of the assessment, using updated statewide summary risk statistics (mean, SD) as the benchmark. To illustrate this, we calculated TriatoScores both including (Additional file 1: Table S5) and excluding (Additional file 1: Table S6) records of the two non-native species known to occur in Bahia-T. infestans and T. rubrofasciata. Importantly, our analyses of the latter dataset are in fact about the "baseline" entomological risk associated with native, and hence non-eliminable, vector species across the state's municipalities (see $[11,20]$ and Table 1). Note also that these analyses are mathematically equivalent to assigning a zero "species relevance score" to $T$. infestans and T. rubrofasciata.

To assess the degree of agreement between our entomological-risk stratification based on TriatoScores and SESAB's official disease-risk stratification [39], we used the $\operatorname{irrCAC} 1.0$ package [48] in $\mathrm{R} 3.6 .3$ [49] to calculate Gwet's $\mathrm{AC}_{2}$ coefficients [50]. Gwet's $\mathrm{AC}_{2}$ suitably deals with ordinal data (via the weights = "ordinal" argument in $\operatorname{irrCAC}$ [48]) and is more robust to variation in rating frequency distributions than commonly used agreement coefficients such as Cohen's $\kappa[50,51]$. We note that comparing risk ratings derived from TriatoScore and SESAB's criteria is somewhat "unfair"-TriatoScore uses only vector data, while SESAB also takes epidemiological, demographic, socioeconomic and environmental information into account [33, 38, 39]. The comparison, however, can be useful if it helps pinpoint municipalities where SESAB's stratification indicates a lower disease risk than the (just) entomological risk suggested by TriatoScores. We also note that integrating additional sources of information into a TriatoScore-based assessment is straightforward-one just needs to add a new weight for each extra metric. To illustrate how this might work, we used housing quality data from the last demographic census (IBGE, 2010; [37]) to calculate, for each municipality, the proportion of houses in poor or very poor condition-a rough measure of dwelling vulnerability to infestation by triatomines [24, 25, 39] (see Additional file 1: Table S2). We then weighted municipal TriatoScores by this housing quality metric, standardized the resulting "TriatoScore-plus" values (to mean 0 and SD 1 as above), and grouped our study municipalities into three risk strata (defined using the \pm 1 SD criterion as above) (Additional file 1: Table S7).

We used ArcMap ${ }^{\circledR} 10.5$ [47] and the data in Additional file 1 to build municipality-scale maps of vector species-specific "weighted presence", vector species richness, TriatoScore and TriatoScore-plus values, and risk strata-both disease-risk strata as per the official SESAB classification and entomological-risk strata based on TriatoScores. Finally, we used the "Hot and Cold Spot Analysis" tool of ArcMap ${ }^{\circledR} 10.5$ [47] to identify and map spatial clusters of municipalities with high ("hotspots") and low ("coldspots") TriatoScore values; these analyses were run with the Getis-Ord $G_{i}^{*}$ statistic [52] and the "contiguity-edges and corners", "row standardization" and "false discovery rate correction" options [47].

\section{Results}

Table 1 lists all triatomine bug species recorded so far in Bahia. Triatomine bugs are known or expected to occur in all of the state's municipalities; the maps in Additional file 2: Figures S1-S24 show the municipality-level distribution of each species, with "weighted presence" values used for native species (see Additional file 1: Tables S1, S3). Our main dataset (including T. infestans records since 2006) reveals a mean richness of $10.2 \pm 2.5 \mathrm{SD}$ species (range, 6-18) per municipality (Fig. 2). Urandi is the municipality with the highest richness (18 species, all native), followed by Candiba, Jacaraci, and Pindaí (16 native species); these species-rich municipalities are located in southwestern Bahia (Fig. 2a). The geographical patterns of 


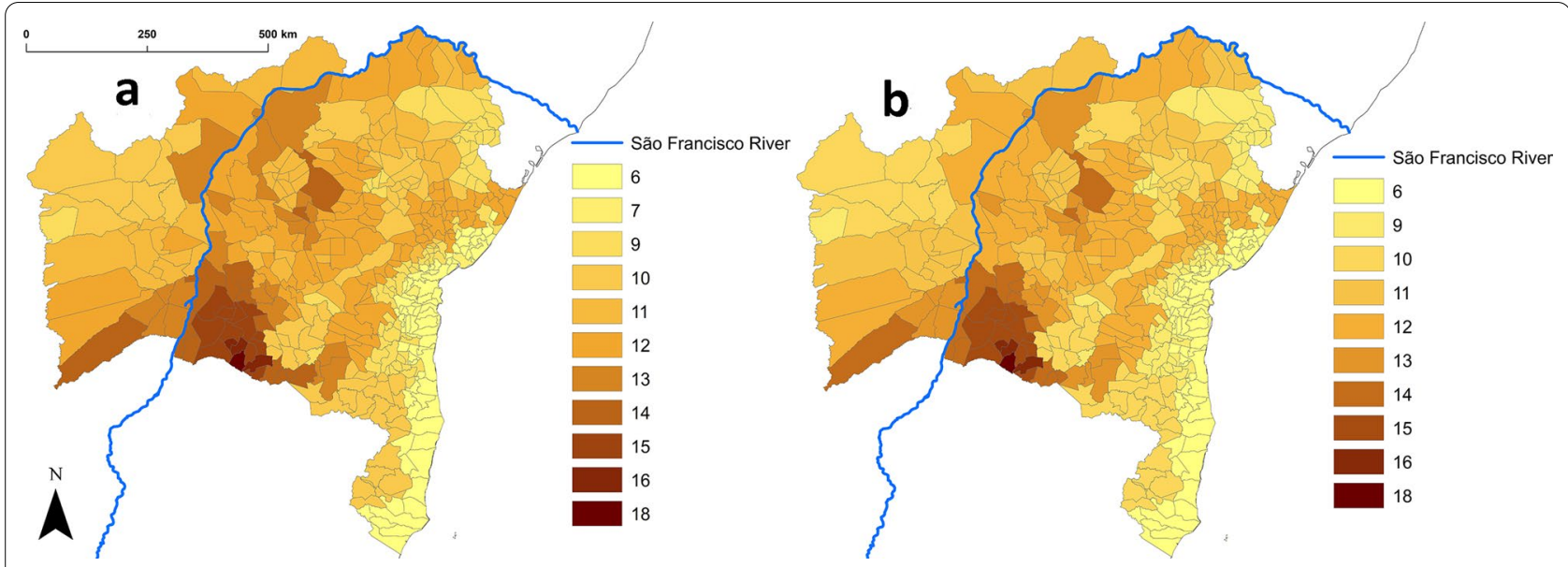

Fig. 2 Spatial patterns of triatomine bug species richness across the 417 municipalities of Bahia state, Brazil. a Including records of non-native species (Triatoma infestans since interruption of Trypanosoma cruzi transmission by this species was certified in 2006 and T. rubrofasciata); $\mathbf{b}$ including only records of native species. Scale: number of species

triatomine bug species richness do not vary substantially when only native species are considered (Fig. 2b). In Bahia, the Brazilian Atlantic dry forest is home to 17 native species, the semiarid Caatinga to 15 , the Cerrado savanna to 11 , and the moister Bahia interior forest to 10 species; in contrast, the coastal Mangroves (where triatomines most likely do not occur in Bahia) and Restingas (two species), as well as the higher-altitude Campos Rupestres montane savannas (three species), have the lowest richness values (Table 2). Municipality-level species richness hence seems to be somewhat higher in the ecoregion-transitional areas that roughly follow the dry San Francisco River valley and its fringes, and is clearly lower along the moister coastal region (Figs. 1, 2).

Vector species richness patterns were also reflected in municipal TriatoScore values (main dataset: mean, $23.7 \pm 7.3$ SD; range, 2.8-44.0; Fig. 3). TriatoScore mapping, however, revealed a clearer pattern of higher entomological risk along the São Francisco River valley and lower entomological risk along the coast; this was true both for the main dataset including non-native species (Fig. 3a) and for the native-species-only dataset (Fig. 3c). Geospatial analyses recovered a sharp hotspot cluster along the São Francisco River and the uplands that bound its valley (especially to the east and north) and a coldspot cluster along the moister coast; again, these results were largely independent of whether all vector species or only native species were considered (Fig. 3b, d). Overall, TriatoScores were higher in municipalities dominated by dry-to-semiarid ecoregions (Caatinga and Atlantic dry forest; mean TriatoScore, $28.8 \pm 3.8 \mathrm{SD}$ ) than in those dominated by savanna-grassland (Cerrado and Campos Rupestres; mean TriatoScore, $25.1 \pm 3.3 \mathrm{SD}$ ) or, especially, by the moist-forest ecoregions along the coast and on coastal ranges (16.7 \pm 5.1 SD; Fig. 4).

Bahia's SESAB official disease-risk stratification and our TriatoScore-based entomological-risk stratification agreed well (Gwet's $\mathrm{AC}_{2}=0.81 \pm 0.02 \mathrm{SE}$ ), with no instances of disagreement involving high/low or low/ high risk strata (Table 3). However, TriatoScore values suggest that the official classification may be underestimating risk in 42 municipalities (Table 3). Importantly, out of 152 municipalities failing to report triatomines to SESAB in 2006-2019, two (Ibiassucê and Lajedinho) had TriatoScores corresponding to high entomological risk and 71 had TriatoScores corresponding to moderate entomological risk (Additional file 1: Table S8). Figure 5 shows entomological-risk strata when TriatoScores are computed using data on all vector species (main dataset) vs. data on native species only; as summarized in Table 3, agreement with Bahia's SESAB official disease-risk classification was again substantial (Gwet's $\mathrm{AC}_{2}=0.79 \pm 0.02$ $\mathrm{SE})$. These results suggest that Bahia's native triatomines (Tables 1,2) can maintain high to moderate risk of vector-borne Chagas disease in 318 (76.3\%) of the state's municipalities (Fig. 5b, Table 3; Additional file 1).

The straightforward derivation of "TriatoScore-plus" values illustrates the potential of our approach to integrate diverse data sources-in our example, data on municipality-level housing quality. This particular extra weight reduces TriatoScores by an amount that is proportional to the share of good-quality houses in each municipality. In our case-study, reductions ranged from nil for five municipalities where that share was zero to 


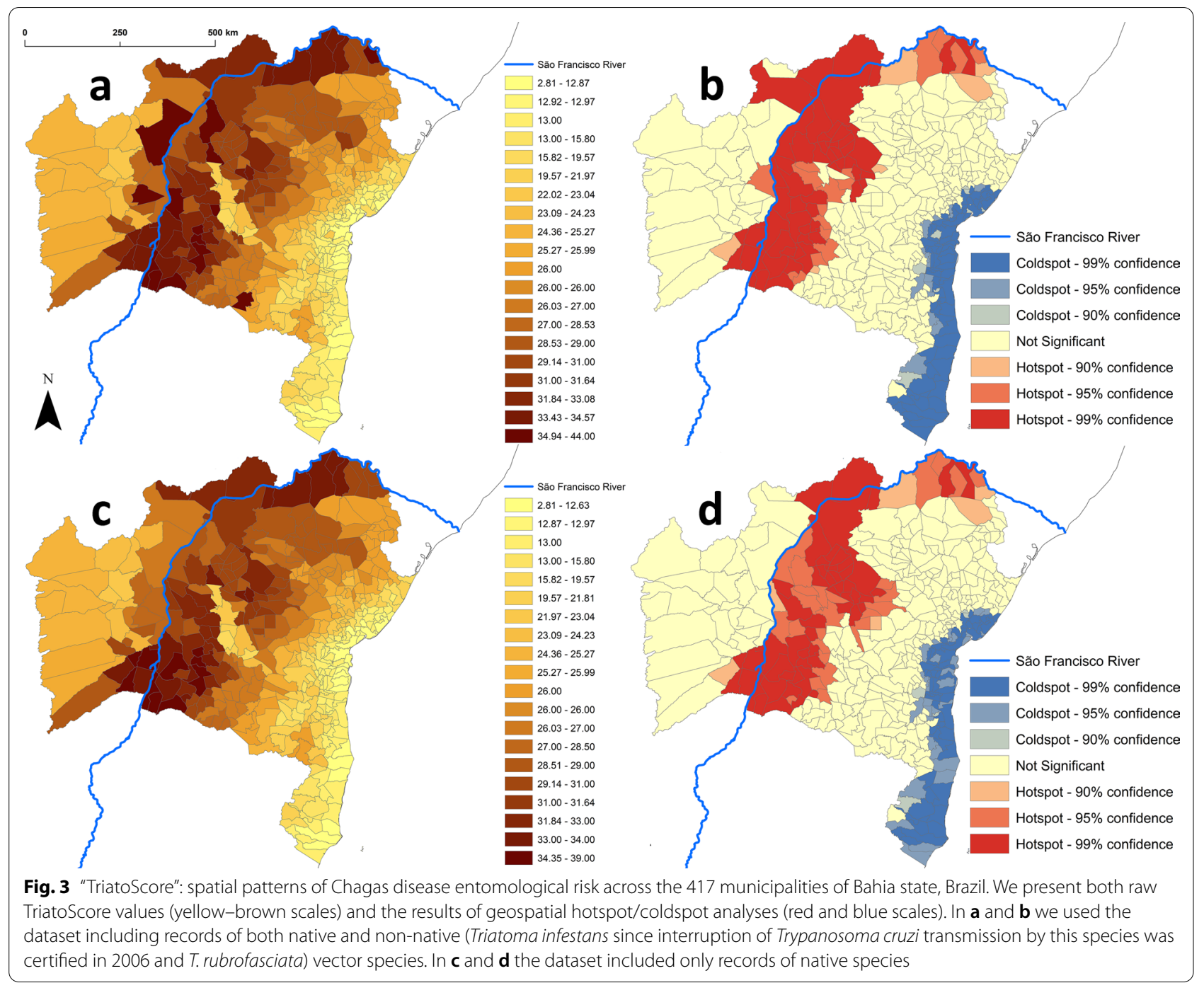

75.5\% for two municipalities (including the state's capital) were most houses were in good condition (see Fig. 6 and Additional file 1: Table S7). Table 4 shows the crossclassification of municipalities into risk strata based on standardized TriatoScore and TriatoScore-plus values. Note how one municipality that was at high entomological risk after TriatoScore moved to the low-risk stratum when housing conditions were considered; this reflects the fact that just $33.7 \%$ of houses were in poor or very poor condition in this municipality-Paulo Afonso, which on the other hand has a dangerous vector fauna including T. juazeirensis/brasiliensis, T. sordida, T. pseudomaculata, Panstrongylus megistus, or P. lutzi (Additional file 1: Tables S1, S2, S5, S7). As with TriatoScore (Table 3), TriatoScore-plus suggests that the official SESAB stratification may in some cases underestimate risk-27 and 13 municipalities that SESAB suggests are at low and moderate disease risk are classified as being at moderate and high risk, respectively, when standardized TriatoScore-plus values are used to define risk strata (Table 4). Overall, Figs. 5 and 6 show how entomological-risk patterns become less tightly associated with biogeographic-ecological features as socioeconomic information is taken into account.

\section{Discussion}

TriatoScore is a single-figure measure of Chagas disease entomological risk that (i) covers both native and non-native triatomine bug species, (ii) tackles the issue of locally incomplete vector-occurrence records, and (iii) is designed to support decision-making at the spatial scale most relevant to decentralized control-surveillance systems. Our approach leverages the best available knowledge on the ecology-behavior and distributionbiogeography of individual triatomine bug species to compute local (e.g., municipal) TriatoScores, which can 


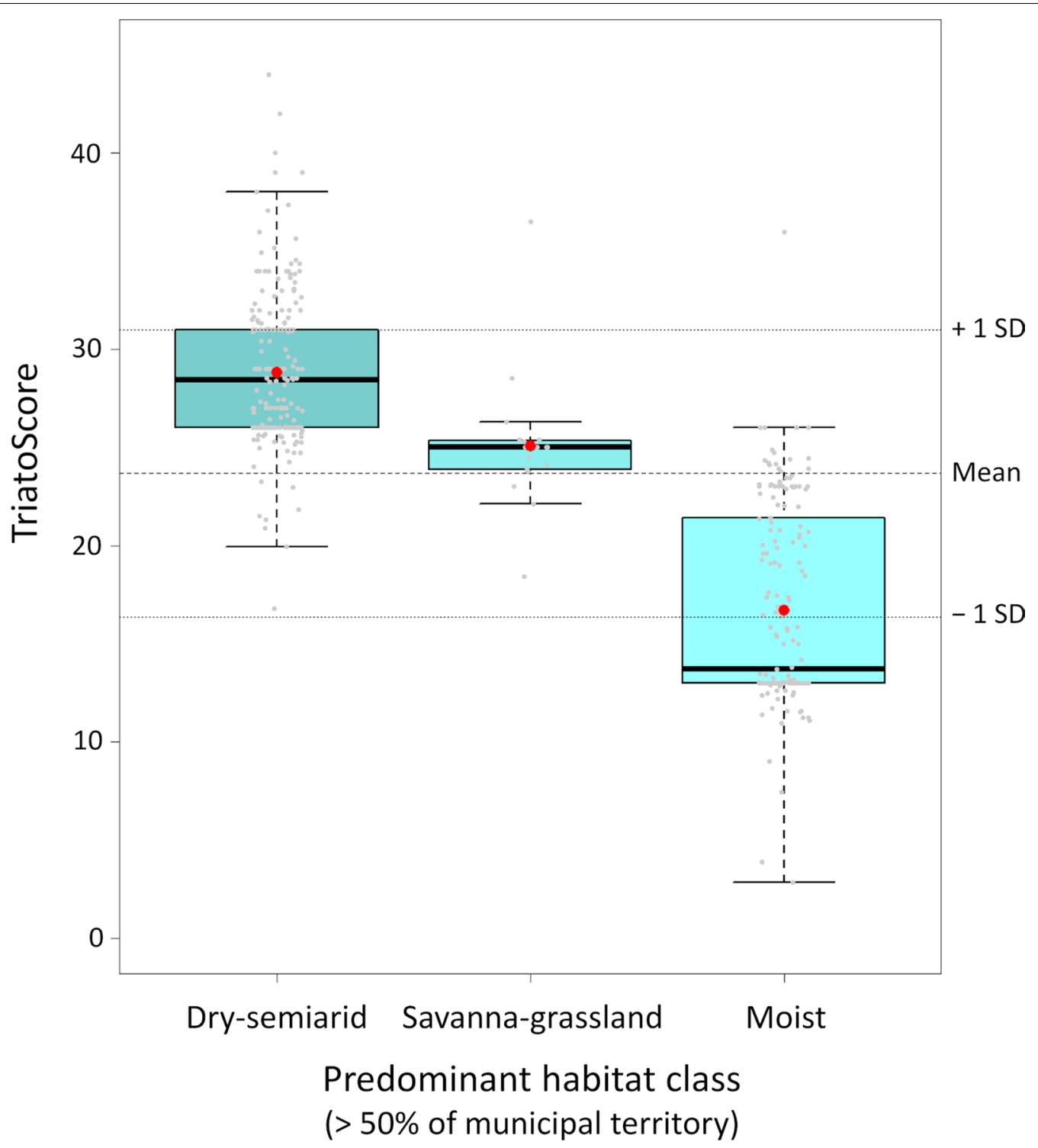

Fig. 4 TriatoScores and predominant habitat classes across the 417 municipalities of Bahia state, Brazil. Grey dots, TriatoScore values for individual municipalities; box plots show medians (thick horizontal lines), inter-quartile ranges (box upper-lower limits), and values that fall within 1.5 times the interquartile range (whiskers); red circles are means. The dotted horizontal lines highlight the overall TriatoScore mean value and the mean \pm 1 standard deviation (SD) band; in our main entomological-risk stratification scheme, we considered municipalities with TriatoScores $>1$ SD above the mean as being at high risk, those with TriatoScores > 1 SD below the mean as being at low risk, and those with values within \pm 1 SD of the mean as being at moderate risk

in turn be used to stratify and map entomological risk over larger spatial units. When based on standardized TriatoScores, risk stratification becomes a fundamentally dynamic exercise-changes in local vector faunas (or in our knowledge about them) are automatically accounted for as local spatial units are reassigned to risk strata relative to the recalculated average risk across all units in the region of interest. Although the most basic version of TriatoScore uses only vector data, integrating epidemiological, demographic, environmental, or operational information is straightforward. TriatoScore may hence become a useful addition to the Chagas disease vector control-surveillance toolbox.

Our approach draws primarily on the hierarchical working classification of Chagas disease vectors put forward by one of us with the suggestion that it was not only simple and biologically sound, but also potentially useful [20] see also [39]. Here, we illustrate how this idea can be 
Table 3 Agreement between the entomological-risk stratification based on TriatoScore and the official Chagas disease-risk stratification of the state's health department (SESAB) across the 417 municipalities of Bahia state, Brazil

\begin{tabular}{lllll}
\hline SESAB (disease risk) & Total & $\%$ \\
\cline { 2 - 4 } & Moderate & High & \\
\hline
\end{tabular}

All species ${ }^{\mathrm{a}}$

TriatoScore (entomological risk)

\begin{tabular}{|c|c|c|c|c|c|}
\hline Low & 76 & 21 & 0 & 97 & 23.2 \\
\hline Moderate & 25 & 176 & 44 & 245 & 58.8 \\
\hline High & 0 & 17 & 58 & 75 & 18.0 \\
\hline Total & 101 & 214 & 102 & 417 & 100 \\
\hline$\%$ & 24.2 & 51.3 & 24.5 & 100 & \\
\hline \multicolumn{6}{|c|}{ Native species ${ }^{b}$} \\
\hline \multicolumn{6}{|c|}{ TriatoScore (entomological risk) } \\
\hline Low & 78 & 21 & 0 & 99 & 23.7 \\
\hline Moderate & 23 & 171 & 50 & 244 & 58.5 \\
\hline High & 0 & 22 & 52 & 74 & 17.8 \\
\hline Total & 101 & 214 & 102 & 417 & 100 \\
\hline$\%$ & 24.2 & 51.3 & 24.5 & 100 & \\
\hline
\end{tabular}

a Estimate of agreement, TriatoScore-all species vs. Bahia state: Gwet's $\mathrm{AC}_{2}=0.81 \pm 0.02 \mathrm{SE}$

${ }^{\mathrm{b}}$ Estimate of agreement, TriatoScore-native species vs. SESAB: Gwet's $\mathrm{AC}_{2}=0.79 \pm 0.02 \mathrm{SE}$

put to work in practice. At the highest level of the hierarchy [20], two triatomine bug species recorded in Bahia are non-native to the state. Triatoma infestans is the most dangerous domestic vector of Chagas disease $[7,11$,
$12,19,20,24,25]$, and was hence given the highest "species relevance score" (Table 1). Triatoma rubrofasciata is strongly associated with rats of the genus Rattus, among which it transmits Trypanosoma conorhini; although it can also support T. cruzi infections, this originally Asian species has limited relevance as a vector of Chagas disease [17, 24-26, 53], and its "species relevance score" is therefore much lower (Table 1). Importantly, these non-native species can and should be targeted for local elimination, and this critical operational consideration sets them apart from the species that are locally native $[12,20,39]$. Native species were given "species relevance scores" ranging from 4 for those known to often breed inside and/or around houses (T. juazeirensis/brasiliensis, T. pseudomaculata, T. sordida, T. lenti/bahiensis and P. megistus) to 1 for those that have only rarely been found invading human dwellings (e.g., Rhodnius domesticus or Parabelminus yurupucu) (see Table 1 and [7, 11, 12, 14-17, 19-21, 24-34, 39]). While the values we chose for scoring are admittedly arbitrary, they reflect our best knowledge about the epidemiological relevance of each species-and, most importantly, the scores' relative sizes reflect the species' relative relevance [20]. In practice, the initial step of our approach thus entails eliciting expert opinion on the relevance of each triatomine bug species known to be present in the region of interest, with special attention paid to relative relevance.

The second general requirement was to map each species' occurrence at the scale of municipalities. We used vector-presence records generated by local surveillance

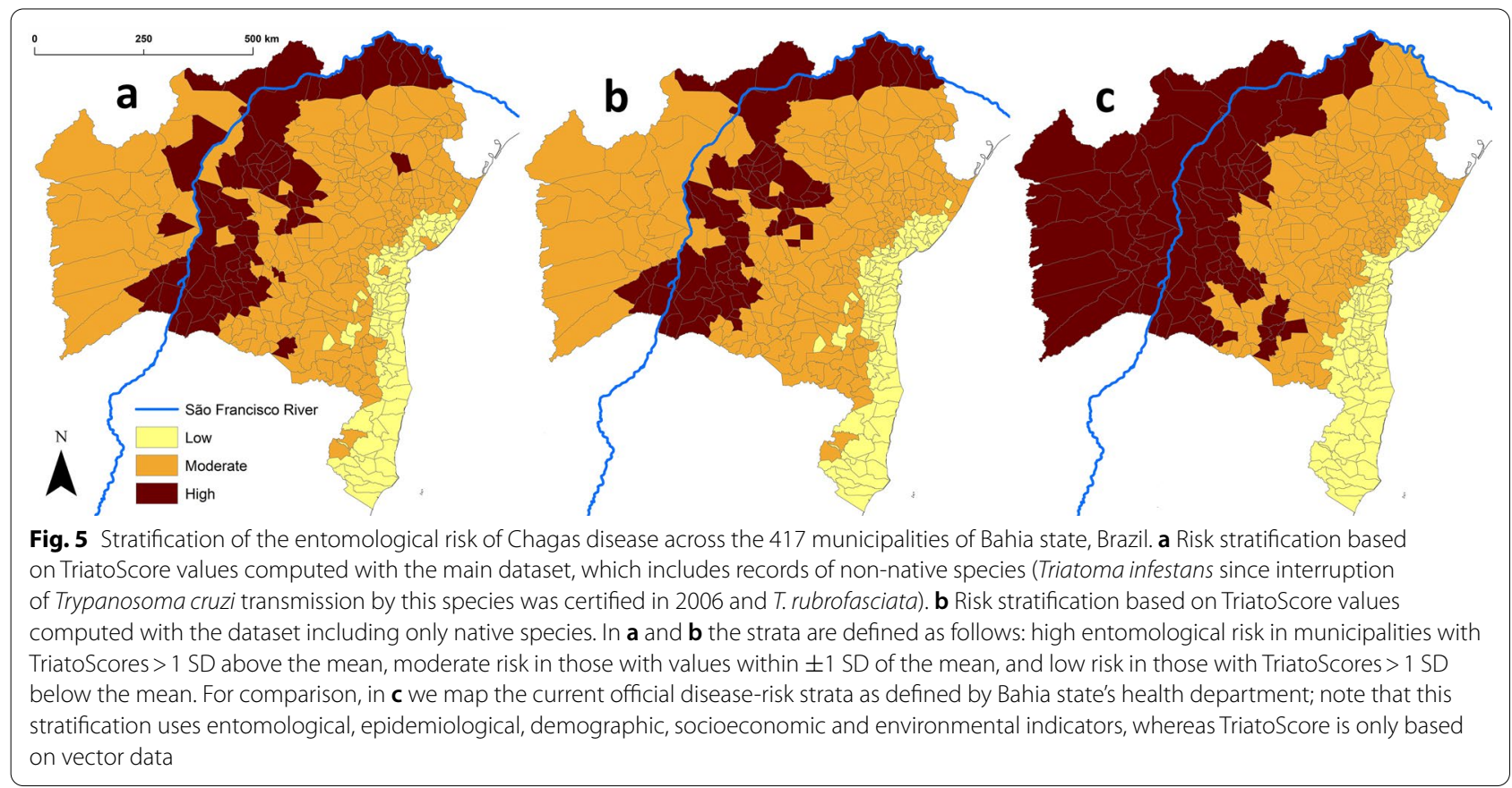




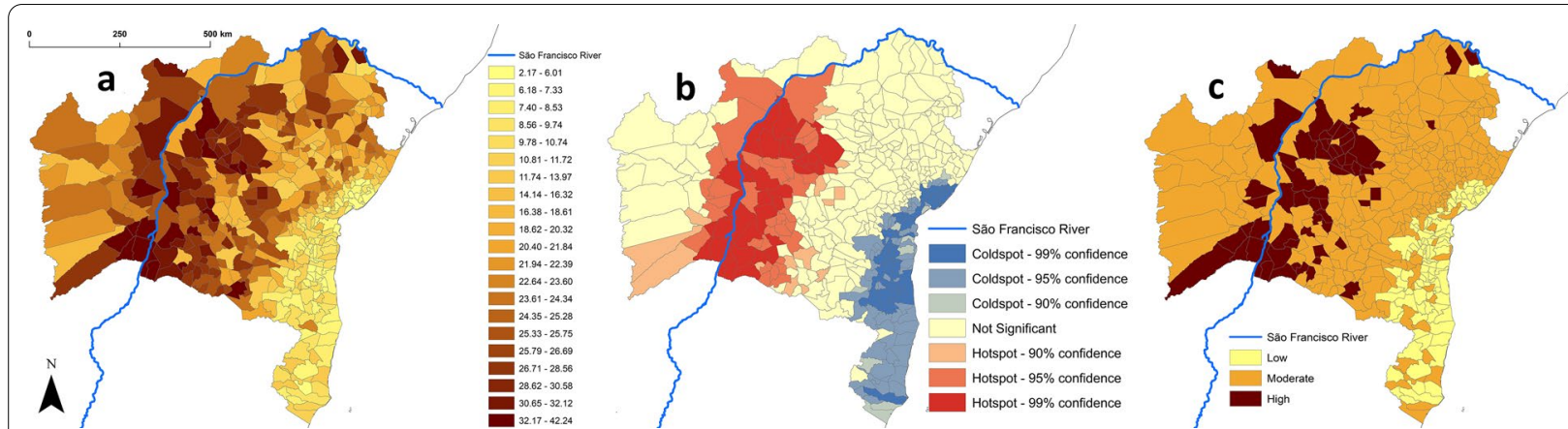

Fig. 6 "TriatoScore-plus": integrating housing quality data into the assessment of entomological risk. a Raw TriatoScore-plus values across the 417 municipalities of Bahia state, Brazil. b Geospatial hotspot/coldspot analysis of TriatoScore-plus values. c Risk strata based on TriatoScore-plus: high risk in municipalities with TriatoScores $>1$ SD above the mean, moderate risk in those with values within \pm 1 SD of the mean, and low risk in those with TriatoScores $>1$ SD below the mean

systems as our main data source, yet as many as 152 municipalities $(36.5 \%)$ did not produce any record over the period 2006-2019-and the tally remains at 125 (or 30\%) when considering the two decades since 1999 (Additional file 1: Table S8). This, of course, could not be taken to mean that triatomines do not occur (and enter houses) in any of those municipalities; rather, the absence of records almost certainly springs from the imperfect functioning of entomological surveillance [13-15, 21]. To fill in the spurious blanks in the species-by-municipality matrices and maps, we complemented this dataset with

Table 4 Agreement between risk stratification schemes based on TriatoScore-plus (which integrates housing quality data) and TriatoScore (only entomological data), and the official Chagas disease-risk classification of the state's health department (SESAB) across the 417 municipalities of Bahia state, Brazil

\begin{tabular}{llllll}
\hline & \multicolumn{2}{l}{ TriatoScore-plus } & Total & $\%$ \\
\cline { 3 - 4 } & Low & Moderate & High & & \\
\hline TriatoScore & & & & & \\
Low & 76 & 21 & 0 & 97 & 23.3 \\
Moderate & 21 & 211 & 13 & 245 & 58.8 \\
High & 1 & 25 & 49 & 75 & 18.0 \\
Total & 98 & 257 & 62 & 417 & 100 \\
$\%$ & 23.5 & 61.6 & 14.9 & 100 & \\
SESAB & & & & & \\
Low & 74 & 27 & 0 & 101 & 24.2 \\
Moderate & 24 & 177 & 13 & 214 & 51.3 \\
High & 0 & 53 & 49 & 102 & 24.5 \\
Total & 98 & 257 & 62 & 417 & 100 \\
$\%$ & 23.5 & 61.6 & 14.9 & 100 & \\
\hline
\end{tabular}

${ }^{a}$ Estimate of agreement, TriatoScore-plus vs. TriatoScore: Gwet's $\mathrm{AC}_{2}=0.86 \pm 0.01 \mathrm{SE}$

${ }^{b}$ Estimate of agreement, TriatoScore-plus vs. SESAB: Gwet's $\mathrm{AC}_{2}=0.79 \pm 0.02 \mathrm{SE}$ records from the literature, including (i) actual occurrence records that we could map to a municipality, (ii) species distribution maps derived from ecological niche models, and (iii) the best available knowledge about the ecoregional biogeography of each species (Table 2) [17, 27-34, 40-45].

This mapping procedure was straightforward for most species, but somewhat challenging for a few (see Table 2 and its footnotes). First, some species are local endemics restricted to a specific subarea within an ecoregion. For example, T. sherlocki seems to be endemic to the JacaréVerde basin and the ranges that bound it $[17,30-33,40]$ (Fig. 1), and T. melanica does not seem to extend into the Cerrado to the northwest of Bahia [17, 30-33, 40, 45] (see Table 2 and Additional file 2: Figures S13, S17). Second, we found that some species occur in municipalities with supposedly unsuitable ecoregional ecologies. For example, T. tibiamaculata, $R$. neglectus, $R$. domesticus and Pa. yиrupucu have been recorded in municipalities with $100 \%$ of the land classified as Caatinga (Table 2). Most such cases are readily explained by the relatively low spatial resolution of available ecoregional classifications-suitable habitat is likely present in small patches not captured by our coarse-scale ecoregion map (Fig. 1). To reflect this "marginal occurrence", we assigned a 0.001 value to the "weighted presence" of $T$. tibiamaculata, $P$. lutzi, $R$. domesticus and $P a$. yurupucu in municipalities with this kind of mismatch between records and ecoregions (see Table 2 and [17, 34]). The case of $R$. neglectus appears to be different-local populations of this species, which is primarily from the Cerrado $[17,24,25,34$, $42,43]$, seem to have adapted to drier Caatinga environments in northern-central Bahia [32, 33, 42] (see Table 2 and Additional file 2: Figure S11). Finally, although $P$. megistus is primarily a moist-forest species, wild populations are also common in drier ecoregions including the 
Cerrado and Caatinga, where they occupy gallery forests and other moister-habitat patches [17, 29]; again, our ecoregional assessment does not capture such fine-scale environmental heterogeneity. The full set of species-specific "weighted presence" maps is presented in Additional file 2: Figures S3-S24, and the data used to build them are available in Additional file 1: Tables S1-S7.

TriatoScore values were overall higher in municipalities dominated by dry-to-semiarid ecoregions, lower in municipalities where moister forests dominate, and intermediate in municipalities dominated by seasonally dry savanna-grassland (Fig. 4). The higher entomological risk in the Caatinga and Atlantic dry forest reflects both a particularly high triatomine species richness (Table 2) and the fact that many of those species are often found infesting or invading houses (Table 1) [7, 11, 12, 15, 17, 19, 24-34, 40-45]. While the eastern portion of the Cerrado that covers western Bahia is also fairly species-rich (Table 2), at least three of the 11 triatomine bug species occurring there (Panstrongylus diasi, Cavernicola pilosa and Psammolestes tertius) are seldom found in or around houses (Table 1) [7, 11, 12, 17, 24-34, 40-45]. In Bahia, the species-rich Caatinga, Atlantic dry forest and Cerrado meet along the São Francisco River valley (Fig. 1), and TriatoScore mapping revealed a pattern of higher entomological risk in that region (Fig. 3). In contrast, the Campos Rupestres montane savannas of the Serra da Mangabeira (Fig. 1) are home to just three triatomine bug species (Table 2) [17, 27-33], and TriatoScore values were accordingly low in ten municipalities (with $\sim 10 \%$ to $\sim 50 \%$ of territory corresponding to Campos Rupestres) located along a southeast-northwest diagonal, narrow strip in the center of the state (Figs. 1, 3). Finally, 6 of the 10 triatomine bug species known to occur in the moister coastal ecoregions do not seem able to stably infest houses (Tables 1, 2) [7, 11, 12, 17, 24-34]. Therefore, TriatoScore values are particularly low along the central and southern coast of Bahia (Fig. 3). Geospatial analyses confirmed these patterns by showing (i) a clear-cut hotspot of higher entomological risk in municipalities along the São Francisco valley and on the ranges that bound it (particularly to the east and north), (ii) a clear-cut coldspot of lower entomological risk in municipalities along the central-southern coast, and (iii) two separate areas of nonsignificant clustering of TriatoScore values: (a) the Cerrado-dominated western region and (b) the Caatingadominated region east of the central uplands (the Serra do Angelim-Chapada Diamantina-Serra da MangabeiraSerra do Espinhaço complex) plus the overall drier northern coast (Figs. 1, 3).

One particularly attractive feature of the TriatoScore approach is that it is fundamentally dynamic. This can be illustrated with a hypothetical example. Suppose that in some year in the near future (i) T. infestans infestation foci are discovered in two municipalities where the species was historically present but from where it was not reported since 2006 (say, Abaré and Anagé), and (ii) intensive but negative searches strongly suggest that $T$. rubrofasciata is no longer present in two municipalities where it was recorded in the past (say, Glória and Jussiape). In Additional file 1: Table S9 we show how these changes can swiftly be incorporated into an exercise of entomological-risk assessment and stratification-by typing the new "species relevance score" values into the appropriate cells (here, "10.0" in cells B4 and B15, and "0.0" in cells C141 and C224; highlighted in red font in Additional file 1: Table S9), TriatoScores are automatically updated and standardized and risk strata automatically recalculated (see columns $\mathrm{Z}$ to $\mathrm{AC}$ in Additional file 1: Table S9). To provide a real-life (if retrospective) example of TriatoScore's flexibility, we examined how the historical elimination of non-native T. infestans from 125 municipalities [27-33] changed entomological-risk patterns across Bahia. We found that TriatoScores were reduced by an average of $26.5 \%$ (range, 20.4-43.5\%) in those municipalities; declines were steeper in municipalities where the "baseline" entomological risk brought about by native vectors is lower (see Additional file 1: Table S10). A further example (this time prospective) is our evaluation of "baseline" risk-what would be the patterns of Chagas disease entomological risk if the two non-native vector species still found in the state were finally eliminated (Figs. 2, 3; Additional file 1: Tables S3, $\mathrm{S} 6, \mathrm{~S} 10)$. In general, thus, our approach can swiftly incorporate new data on local-scale vector-species distribution. Note also that to quickly identify municipalities where risk is much higher or much lower than average one just needs to tinker with the threshold used to define risk strata. For example, a $\pm 1.5 \mathrm{SD}$ criterion highlights 14 municipalities with very high, and 20 with very low, entomological risk (Additional file 1: Table S11).

Finally, we again draw attention to the fact that the basic version of TriatoScore we have presented uses only vector data, yet Chagas disease transmission risk depends on a constellation of social, cultural, economic, demographic, ecological, environmental, political, and operational determinants $[7,23,24,39,54-56]$. For example, and as Carlos Chagas vividly described in his 1909 paper [57], poor-quality housing sets the stage for frequent contact between vectors and humans [58]. It would therefore be of interest to develop a more elaborate version of TriatoScore in which metrics describing further potential determinants of transmission could be incorporated (see, e.g., [39]). As we have shown with our computation of municipal "TriatoScore-plus" values, this is straightforward enough-all that is needed is a set of weights, one 
for each putative determinant, derived from measurements taken at the scale of interest (Fig. 6). We chose to illustrate this procedure with a municipality-level measure of housing conditions, but many other possibilities could merit consideration [39]. A non-exhaustive list of examples might include local-scale measures of (i) the frequencies of dwelling infestation with triatomines or of T. cruzi infection in humans or vectors; (ii) the levels of poverty or human development; (iii) the patterns and dynamics of land-use change and deforestation; (iv) the demographics of urban/rural populations; or (v) whether control-surveillance systems are adequately funded, staffed, and operated in each municipality.

\section{Conclusions}

Chagas disease is caused by a multi-host zoonotic pathogen transmitted by over 100 locally native vector species, many of which persistently invade and infest houses from the USA to Argentina [7, 11, 12, 17, 19]. Completely interrupting T. cruzi transmission is therefore unfeasible $[11,12]$. Instead, decades of hard-won experience clearly indicate that disease control, defined as the "reduction of [...] incidence, prevalence, morbidity and/or mortality to a locally acceptable level" [59], is the most that we can aim for in the Americas [11]. Long-term vector controlsurveillance has a major role to play in disease control $[11,12,14]$, and entomological-risk stratification and mapping is and will remain a key tool for local program managers [11, 12, 20]. TriatoScore provides a sound, dynamic, and flexible means to this end-and one that, moreover, can be easily extended to integrate operationally relevant information beyond vector data.

\section{Abbreviation}

SESAB: Bahia's state health department.

\section{Supplementary Information}

The online version contains supplementary material available at https://doi. org/10.1186/s13071-021-04954-5.

\footnotetext{
Additional file 1: Table S1. Vector presence and species richness (columns AB, AC). Table S2. Ecoregions and housing quality. Table S3. "Weighted presence" (native vectors). Table S4. "Weighted scores" and "TriatoScores" (column Z). Table S5. "TriatoScores" and risk strata (with Triatoma infestans since 2006). Table S6. "TriatoScores" and risk strata (native species only). Table S7. "TriatoScore-plus" values and risk strata. Table S8. Municipalities with no vector records from surveillance (red font, 1999-2019; black font, 2006-2019). Table S9. Hypothetical scenario: "weighted scores" and "TriatoScores" (column Z). Table S10. "TriatoScore" changes with the elimination of Triatoma infestans. Table S11. "TriatoScores" and extreme-risk strata ( $\pm 1.5 \mathrm{SD}$ criterion) (with T. infestans since 2006). Triatomine bug species occurrence based on routine controlsurveillance records (SESAB, 1999-2019) and published reports [17, 27-29, 29-31, 31-34, 40-45].

Additional file 2: Figure S1. Triatoma infestans in Bahia, Brazil (since 2006). Figure S2. Triatoma rubrofasciata in Bahia, Brazil (as reported).
}

Figure S3. Triatoma juazeirensis/brasiliensis in Bahia, Brazil ("weighted presence"). Figure S4. Triatoma sordida in Bahia, Brazil ("weighted presence"). Figure S5. Triatoma pseudomaculata in Bahia, Brazil ("weighted presence"). Figure S6. Panstrongylus megistus in Bahia, Brazil ("weighted presence"). Figure S7. Triatoma lenti/bahiensis in Bahia, Brazil ("weighted presence"). Figure S8. Triatoma vitticeps in Bahia, Brazil ("weighted presence"). Figure S9. Triatoma costalimai in Bahia, Brazil ("weighted presence"). Figure S10. Panstrongylus lutzi in Bahia, Brazil ("weighted presence"). Figure S11. Rhodnius neglectus in Bahia, Brazil ("weighted presence"). Figure S12. Rhodnius nasutus in Bahia, Brazil ("weighted presence"). Figure S13. Triatoma melanica in Bahia, Brazil ("weighted presence"). Figure S14. Triatoma tibiamaculata in Bahia, Brazil ("weighted presence"). Figure S15. Panstrongylus geniculatus in Bahia, Brazil ("weighted presence"). Figure S16. Triatoma petrocchiae in Bahia, Brazil ("weighted presence"). Figure S17. Triatoma sherlocki in Bahia, Brazil ("weighted presence"). Figure S18. Triatoma melanocephala in Bahia, Brazil ("weighted presence"). Figure S19. Panstrongylus diasi in Bahia, Brazil ("weighted presence"). Figure S20. Panstrongylus lenti in Bahia, Brazil ("weighted presence"). Figure S21. Cavernicola pilosa in Bahia, Brazil ("weighted presence"). Figure S22. Rhodnius domesticus in Bahia, Brazil ("weighted presence"). Figure S23. Psammolestes tertius in Bahia, Brazil ("weighted presence"). Figure S24. Parabelminus yurupucu in Bahia, Brazil ("weighted presence"). Triatomine bug species occurrence based on routine control-surveillance records (SESAB, 1999-2019) and published reports [17, 27-29, 29-31, 31-34, 40-45].

\section{Acknowledgements}

Staff of the Epidemiological Surveillance Office at Bahia's state health department curated the SESAB triatomine bug surveillance database we used. We thank Rafaella Albuquerque Silva, Etienne Waleckx and César Augusto Cuba Cuba for suggestions and comments.

\section{Authors' contributions}

GR-Jr, FA-F, RG-G and MGR conceived the study. MGR raised funds and administered the project. GR-Jr, FA-F, RBR, RG-G and MGR contributed to the design of the methods. GR-Jr, FA-F, CMMC, GMC, OMFS, CGSS, EOLF and RFS performed research. GR-Jr, RBR, CMMC, GMC, OMFS, CGSS, and RFS obtained and organized databases. GR-Jr, FAF and RG-G curated the dataset and analyzed the data. GR-Jr, FA-F, RG-G and MGR drafted the first version of the manuscript. All authors contributed to the interpretation of results, read and commented on manuscript drafts, and approved the final version.

\section{Funding}

Fundação de Amparo à Pesquisa do Estado da Bahia (FAPESB) \# 0142013 (PET0023/2013), PROEP/CPqGM, process 400904/2013-6, Fiocruz BahiaIGM-scientific initiation scholarship. The funders had no role in study design, data collection, data analysis, data interpretation, writing of the report, or in the decision to submit the paper for publication.

Availability of data and materials

All data are available in the article and its Additional files.

\section{Declarations}

\section{Ethics approval and consent to participate}

The project was reviewed and approved by the Research Ethics Committee of the Gonçalo Moniz Institute-Fiocruz Bahia, Ministry of Health, Brazil (\# 2.552.284).

\section{Consent for publication}

Not applicable.

\section{Competing interests}

The authors declare that there are no conflicts of interest associated with this study.

\section{Author details}

${ }^{1}$ Instituto Gonçalo Moniz, Fiocruz Bahia, Salvador, Bahia, Brazil. ${ }^{2}$ Núcleo de Medicina Tropical, Faculdade de Medicina, Universidade de Brasília, Brasília, 
Distrito Federal, Brazil. ${ }^{3}$ Coordenação Geral de Vigilância de Zoonoses e Doenças de Transmissão Vetorial, Secretaria de Vigilância em Saúde, Ministério da Saúde, Brasília, Distrito Federal, Brazil. Instituto de Tecnologias da Saúde, Centro Universitário SENAI CIMATEC, Salvador, Bahia, Brazil. ${ }^{5}$ Laboratório Central de Saúde Pública Prof. Gonçalo Moniz, Secretaria de Saúde do Estado da Bahia, Salvador, Bahia, Brazil. ${ }^{6}$ Centro de Atenção à Saúde José Maria de Magalhães Neto, Secretaria de Saúde do Estado da Bahia, Salvador, Bahia, Brazil. ${ }^{7}$ Universidade Salvador-UNIFACS, Salvador, Bahia, Brazil. ${ }^{\circ}$ Laboratório de Parasitologia Médica e Biologia de Vetores, Faculdade de Medicina, Universidade de Brasília, Brasília, Distrito Federal, Brazil. ${ }^{9}$ Faculdade de Medicina da Bahia, Universidade Federal da Bahia, Salvador, Bahia, Brazil. ${ }^{10}$ Yale School of Public Health, Yale University, New Haven, CT, USA.

\section{Received: 16 September 2020 Accepted: 14 August 2021}

Published online: 25 September 2021

\section{References}

1. Murray CJL. Towards good practice for health statistics: lessons from the Millennium Development Goal health indicators. Lancet. 2007;369:862-73.

2. Global Burden of Diseases Study (GBD) 2019 Viewpoint Collaborators. Five insights from the Global Burden of Disease Study 2019. Lancet. 2020;396:1135-59.

3. Anand S, Sen AK. Human Development Index: methodology and measurement. Human development report occasional papers vol. 12. New York: United Nations Development Programme; 1994.

4. World Health Organization-WHO/TDR. Dengue: guidelines for diagnosis, treatment, prevention and control—new edition. Geneva: World Health Organization; 2009.

5. World Health Organization-WHO. Guidelines for malaria. Geneva: World Health Organization; 2021.

6. World Health Organization-WHO. Control of the leishmaniases: report of a meeting of the WHO Expert Committee on the Control of Leishmaniases. Geneva: World Health Organization; 2010.

7. World Health Organization-WHO. Control of Chagas disease. Second report of the WHO Expert Committee. WHO Tech Rep Ser, vol. 905. Geneva: World Health Organisation; 2002. p. 1-109.

8. World Health Organisation. Control, interrupción de la transmisión y eliminación de la enfermedad de Chagas como problema de salud pública. Guía de evaluación, verificación y validación. Washington: Organización Panamericana de la Salud; 2019.

9. GBD Disease and Injury Incidence and Prevalence Collaborators. Global, regional, and national incidence, prevalence, and years lived with disability for 354 diseases and injuries for 195 countries and territories, 1990-2017: a systematic analysis for the Global Burden of Disease Study 2017. Lancet. 2018;2018(392):1789-858.

10. Global Burden of Disease Collaborative Network. Global burden of disease study 2019 (GBD 2019) results. Seattle: Institute for Health Metrics and Evaluation (IHME); 2020. http://ghdx.healthdata.org/gbd-results-tool. Accessed 15 Dec 2020.

11. Rojas de Arias A, Monroy C, Guhl F, Sosa-Estani S, Santos WS, AbadFranch F. Chagas disease control-surveillance in the Americas: the multinational initiatives and the practical impossibility of interrupting vector-borne Trypanosoma cruzi transmission. Mem Inst Oswaldo Cruz. 2021;116:e210130.

12. Abad-Franch F, Diotaiuti L, Gurgel-Gonçalves R, Gürtler RE. Certifying the interruption of Chagas disease transmission by native vectors: cui bono? Mem Inst Oswaldo Cruz. 2013;108:251-4.

13. Abad-Franch F, Diotaiuti L, Gurgel-Gonçalves R, Gürtler RE. Reply—on bugs and bias: improving Chagas disease control assessment. Mem Inst Oswaldo Cruz. 2014;109:125-30.

14. Rojas de Arias A, Abad-Franch F, Acosta N, López E, González N, Zerba E, et al. Post-control surveillance of Triatoma infestans and Triatoma sordida with chemically-baited sticky traps. PLoS Negl Trop Dis. 2012;6:e1822.

15. Abad-Franch F, Valença-Barbosa C, Sarquis O, Lima MM. All that glisters is not gold: sampling-process uncertainty in disease-vector surveys with false-negative and false-positive detections. PLoS Negl Trop Dis. 2014;8:e3187.
16. Minuzzi-Souza TTC, Nitz N, Cuba CAC, Hagström L, Hecht MM, Santana C, et al. Surveillance of vector-borne pathogens under imperfect detection: lessons from Chagas disease risk (mis)measurement. Sci Rep. 2018;8:151.

17. Monteiro FA, Weirauch C, Felix M, Lazoski C, Abad-Franch F. Evolution, systematics, and biogeography of the Triatominae, vectors of Chagas disease. Adv Parasitol. 2018;99:265-344.

18. Abad-Franch F, Gurgel-Gonçalves R. The ecology and natural history of wild Triatominae in the Americas. In: Guarneri AA, Lorenzo MG, editors. Triatominae: the biology of Chagas disease vectors. Entomology in focus, vol. 5. Cham: Springer; 2021. p. 387-445.

19. Waleckx E, Gourbière S, Dumonteil E. Intrusive versus domiciliated triatomines and the challenge of adapting vector control practices against Chagas disease. Mem Inst Oswaldo Cruz. 2015;110:324-38.

20. Abad-Franch F. A simple, biologically sound, and potentially useful working classification of Chagas disease vectors. Mem Inst Oswaldo Cruz. 2016:111:649-51.

21. Abad-Franch F, Vega MC, Rolón MS, Santos WS, Rojas de Arias A. Community participation in Chagas disease vector surveillance: systematic review. PLoS Negl Trop Dis. 2011;5:e1207.

22. Atun R, de Andrade LOR, Almeida G, Cotlear D, Dmytraczenko T, Frenz $P$, et al. Health-system reform and universal health coverage in Latin America. Lancet. 2018;385:1230-47.

23. Yadón Z, Gürtler R, Tobar F, Médici AC, editors. Descentralización y gestión del control de enfermedades transmisibles en América Latina. PAHO/ WHO: Buenos Aires; 2006.

24. Lent H, Wygodzinsky P. Revision of the Triatominae (Hemiptera, Reduviidae), and their significance as vectors of Chagas' disease. Bull Am Mus Nat Hist. 1979;163:123-520.

25. Barrett TV. Advances in triatomine bug ecology in relation to Chagas' disease. In: Harris KH, editor. Advances in disease vector research, vol. 8. New York: Springer; 1991. p. 143-76.

26. Dujardin J-P, Schofield CJ, Panzera F. Los vectores de la enfermedad de Chagas. Brussels: Academie Royale des Sciences D'outre Mer; 2002.

27. Sherlock I, Serafim EM. Fauna Triatominae no Estado da Bahia, Brasil: as espécies e distribuição geográfica. Rev Soc Bras Med Trop. 1972;6:265-76.

28. Silveira AC, Feitosa VM, Borges R. Distribution of triatominae captured in a domestic environment, 1975/83. Brazil Rev Bras Malariol D Trop. 1984;36:15-312.

29. Gurgel-Gonçalves R, Galvão C, Costa J, Peterson AT. Geographic distribution of Chagas disease vectors in Brazil based on ecological niche modeling. J Trop Med. 2012;2012:705326.

30. Ceccarelli S, Balsalobre A, Medone P, Cano ME, Gurgel Gonçalves R, Feliciangeli D, et al. DataTri, a database of American triatomine species occurrence. Sci Data. 2018;5:180071.

31. Gurgel-Gonçalves RC, Galvão C, Mendonça J, Neto EMC. Guia de Triatomíneos da Bahia. Feira de Santana: UEFS Editora; 2012.

32. Sousa OMFD, Santos CGSD, Santos RFD, Fonseca EOL, Lima AGD. Triatomíneos da Bahia: manual de identificação e orientações para o serviço. Salvador: Oxente; 2020.

33. Galvão C, editor. Vetores da doença de Chagas no Brasil. Zoologia: guias e manuais de identificação. Sociedade Brasileira de Zoologia: Curitiba; 2014.

34. Abad-Franch F, Monteiro FA, Jaramillo N, Gurgel-Gonçalves R, Dias FBS, Diotauiti L. Ecology, evolution, and the long-term surveillance of vectorborne Chagas disease: a multi-scale appraisal of the tribe Rhodniini (Triatominae). Acta Trop. 2009;110:159-77.

35. Dinerstein E, Olson D, Joshi A, Vynne C, Burgess ND, Wikramanayake E, et al. An Ecoregion-based approach to protecting half the Terrestria Realm. Bioscience. 2017;67:534-45.

36. Ecoregions 2017. https://ecoregions2017.appspot.com/. Accessed 15 Dec 2020.

37. Instituto Brasileiro de Geografia e Estatística-IBGE. Bahia. https://cidad es.ibge.gov.br/brasil/ba/panorama. Accessed 01 June 2020.

38. Secretaria de Saúde do Estado da Bahia-SESAB. Boletim epidemiológico da doença de Chagas, vol. 1. Salvador: Secretaria de Saúde do Estado da Bahia-SESAB; 2018. p. 1-4.

39. Silveira AC. Enfoque de riesgo en actividades de control de triatomineos. Rev Patol Trop. 2004;33:193-206.

40. Costa J, Dornak LL, Almeida CA, Peterson AT. Distributional potential of the Triatoma brasiliensis species complex at present and under scenarios of future climate conditions. Parasite Vectors. 2014;7:238. 
41. Gurgel-Gonçalves R, Cuba CAC. Predicting the potential geographical distribution of Rhodnius neglectus (Hemiptera, Reduviidae) based on ecological niche modeling. J Med Entomol. 2009;46:952-60.

42. Batista TA, Gurgel-Gonçalves R. Ecological niche modelling and differentiation between Rhodnius neglectus Lent, 1954 and Rhodnius nasutus Stål, 1859 (Hemiptera: Reduviidae: Triatominae) in Brazil. Mem Inst Oswaldo Cruz. 2009;104:1165-70.

43. Gurgel-Gonçalves R, Silva RB. Analysis of the geographical distribution of Psammolestes Bergroth (Hemiptera: Heteroptera: Reduviidae: Triatominae) in South America, with new records of Psammolestes tertius Lent \& Jurberg. Zootaxa. 2009;2033:41-8.

44. Gurgel-Gonçalves R, Ferreira JBC, Rosa AF, Bar ME, Galvão C. Geometric morphometrics and ecological niche modelling for delimitation of nearsibling triatomine species. Med Vet Entomol. 2011;25:84-93.

45. Souza RCM, Campolina-Silva GH, Bezerra CM, Diotaiuti L, Gorla DE. Does Triatoma brasiliensis occupy the same environmental niche space as Triatoma melanica? Parasite Vectors. 2015;8:361.

46. Instituto Brasileiro de Geografia e Estatística - IBGE. Malha municipal. https://www.ibge.gov.br/geociencias/organizacao-do-territorio/malhasterritoriais/15774-malhas.html. Accessed 15 Dec 2020.

47. Shaner J, Wrightsell J. Editing in ArcMap. New York: ESRI; 2000.

48. Gewt KL. Package 'irrCAC'. 2019. https://cran.r-project.org/web/packages/ irrCAC/irrCAC.pdf. Accessed 15 Dec 2020.

49. R Development Core Team. R: a language and environment for statistical computing. Version 3.6.3. Vienna: R Foundation for Statistical Computing. 2020. https://www.R-project.org. Accessed 15 Mar 2020.

50. Gwet KL. Handbook of inter-rater reliability: the definitive guide to measuring the extent of agreement among multiple raters. 4th ed. Gaithersburg: Advanced Analytics, LLC; 2014

51. Quarfoot D, Levine RA. How robust are multirater interrater reliability indices to changes in frequency distribution? Am Stat. 2016:70:373-84.
52. Wang Z, Lam NS. Extending Getis-Ord statistics to account for local space-time autocorrelation in spatial panel data. Prof Geogr. 2020;72:411-20.

53. Dujardin J-P, Lam TX, Khoa PT, Schofield CJ. The rising importance of Triatoma rubrofasciata. Mem Inst Oswaldo Cruz. 2015;110:319-23.

54. Briceño-León R, Méndez GJ. The social determinants of Chagas disease and the transformations of Latin America. Mem Inst Oswaldo Cruz. 2007;102:109-12

55. Gürtler RE, Yadón ZE. Eco-bio-social research on community-based approaches for Chagas disease vector control in Latin America. Trans R Soc Trop Med Hyg. 2015;109:91-8.

56. Ventura-Garcia L, Roura M, Pell C, Posada E, Gascón J, Aldasoro E, et al. Socio-cultural aspects of Chagas disease: a systematic review of qualitative research. PLoS Negl Trop Dis. 2013;7:e2410.

57. Chagas C. Nova Trypanozomiaze humana. Estudos sobre a morfologia e o ciclo evolutivo do Schizotrypanum cruzi n. gen., n. sp., ajente etiologico de nova entidade morbida no homem. Mem Inst Oswaldo Cruz. 1909;1:159-218.

58. Briceño-León R. La casa enferma: sociología de la enfermedad de Chagas. Caracas: Fondo Editorial Acta Científica de Venezuela y Consorcio de Ediciones Capriles; 1990.

59. World Health Organization-WHO. Ending the neglect to attain the Sustainable Development Goals: A road map for neglected tropical diseases 2021-2030. Geneva: World Health Organization; 2020.

\section{Publisher's Note}

Springer Nature remains neutral with regard to jurisdictional claims in published maps and institutional affiliations.
Ready to submit your research? Choose BMC and benefit from:

- fast, convenient online submission

- thorough peer review by experienced researchers in your field

- rapid publication on acceptance

- support for research data, including large and complex data types

- gold Open Access which fosters wider collaboration and increased citations

- maximum visibility for your research: over $100 \mathrm{M}$ website views per year

At BMC, research is always in progress.

Learn more biomedcentral.com/submissions 